Scientific Investigation in Dentistry - SID

\title{
Revisão de literatura
}

\section{O USO DE BIOMATERIAL COMPOSTO POR $\beta$-TCP E PLGA EM TRATAMENTO REGENERATIVO DE LESÕES DE FURCA GRAU II EM MOLARES MANDIBULARES - REVISÃO DE LITERATURA}

\section{The use of biomaterial composed by $\beta-T C P$ and PLGA in regenerative treatment of Grade II furca injuries in mandibular molars - literature review}

\author{
Brenda Lopes Gonçalves ${ }^{1}$; Eduarda Lyssa Ribeiro Silva ${ }^{2}$; Gabriele Nunes \\ Dias $^{3}$; José Cláudio Motão ${ }^{4}$; Luiz Guilherme Freitas de Paula ${ }^{5}$.
}

\begin{abstract}
'Acadêmico do Curso de Odontologia, Centro Universitário de Anápolis - UniEVANGÉLICA, Brasil. ${ }^{2}$ Acadêmico do Curso de Odontologia, Centro Universitário de Anápolis - UniEVANGÉLICA, Brasil. ${ }^{3}$ Acadêmico do Curso de Odontologia, Centro Universitário de Anápolis - UniEVANGÉLICA, Brasil.

${ }^{4}$ Professor Mestre da disciplina de Periodontia no curso de odontologia no Centro Universitário de Anápolis UniEVANGÉLICA, Brasil. Membro da Academia Brasileira de Osseointegração. Coordenador da Liga de Periodontia da UniEvangélica de Anápolis GO.

${ }^{5}$ Doutor em implantodontia pela faculdade de Odontologia de Araraquara. Especialista e mestre em Periodontia.
\end{abstract}

Informação sobre o manuscrito

Recebido em: 11 Mai 2020

Aceito em: 23 Out 2020

\author{
Autor para contato: \\ José Cláudio Motão \\ Av. Universitária, s/n - Cidade Universitária \\ Anápolis - GO \\ Telefone: +55 62999956167
}

E-mail: joseclaudiomotao@yahoo.com.br

\begin{abstract}
RESUMO
Objetivo: Este estudo tem por objetivo avaliar um biomaterial composto por $\beta$-TCP e PLGA em tratamento regenerativo de furca grau II em molares mandibulares. Método: Foram utilizados estudos científicos publicados no período de 2000 a 2020 em inglês e português nas bases de dados PubMed, Scielo e Semantic Scholar. A busca na base de dados resultou em 84 artigos e após a leitura e análise destes, foram selecionados 23 trabalhos que atenderam ao objetivo desta revisão de literatura. Discussão: Materiais não absorvíveis limitam a formação óssea e os mecanismos biológicos que configuram o processo de cicatrização do tecido, inclusive nas situações de enxertia. Assim, os materiais aloplásticos ou reabsorvíveis, são cada vez mais usados como substitutos ósseos, por serem biologicamente compatíveis com os tecidos adjacentes, além de induzirem o crescimento e remodelação óssea, mantendo a homeostasia e as características essenciais dos tecidos ósseos. Dentre os biomateriais citados, $\beta-T C P$ e PLGA, demonstraram resultados satisfatórios nas regenerações teciduais e ósseas guiadas em casos de furca e procedimentos de enxertia, por apresentarem características ideais, como biocompatibilidade, biorreabsorção e osteocondução. Conclusão: $O$ beta-tricálcio fosfato em união ao PLGA (vitaGraft), constitui um material viável para procedimentos de enxertia elou regeneração periodontal de lesões de furca em dentes posteriores mandibulares.
\end{abstract}

\section{PALAVRAS-CHAVE}

Defeitos de furca;Regeneração periodontal; Membrana periodontal;Beta-TCP.

\section{INTRODUÇÃO}

A doença periodontal é uma condição inflamatória crônica que afeta os tecidos de suporte dos dentes, levando à perda óssea e do ligamento periodontal. O desenvolvimento da doença dependerá do tipo de bactéria presente, da resposta imune do hospedeiro e dos fatores locais que 
causam acúmulo de biofilme bacteriano ${ }^{1-3}$. Em dentes posteriores, a progressão da doença periodontal pode ocasionar reabsorção óssea na área de bi ou trifurcação de um dente de múltiplas raízes, sendo este considerado como envolvimento de furca ${ }^{3-5}$. A furca é uma área que devido a morfologia anatômica complexa, limita o acesso à região através de instrumentos de tratamento periodontal convencional. Evidências científicas indicam que os dentes molares são mais afetados com envolvimento de furca e são extraídos com maior frequência provavelmente devido à sua anatomia ${ }^{3-6}$.

Os defeitos de furca são geralmente classificados nos graus I, II ou III, de acordo com a perda óssea horizontal ${ }^{1}$ ou através de características como morfologia, perda óssea vertical e horizontal $^{2}$. É bem estabelecido que o envolvimento da furca, especificamente os graus II e III, aumenta consideravelmente 0 risco de perda dentária ${ }^{3}$. Assim, é de extrema importância determinar a extensão da furca envolvida para diagnóstico apropriado e elaboração de um plano de tratamento. ${ }^{11}$

Como para qualquer lesão periodontal, o tratamento dos dentes com lesões com envolvimento de furca é focado na redução de carga bacteriana supra e subgengival, através de instruções de higiene e terapia periodontal não cirúrgica, com o objetivo de eliminar o biofilme bacteriano das superfícies radiculares afetadas. O tratamento de um dente com múltiplas raízes com envolvimento de furca ainda é um desafio e um problema que, até o momento, não foi resolvido. O tipo de dente e o grau de envolvimento da furca foram definidos como os fatores mais importantes que influenciam esta decisão. ${ }^{4}$

Defeitos de furca podem ser um dos critérios considerados pelos dentistas para indicar a extração de dentes periodontalmente envolvidos ${ }^{3}$ e seus tratamentos são considerados desafiadores. O acesso à região de furca é difícil tanto para o dentista quanto ao paciente, e seu tratamento envolve debridamento para procedimentos de regeneração. ${ }^{8}$

Evidências substanciais indicam que, independentemente da idade, a gravidade da doença periodontal e a mortalidade dentária são mais pronunciadas nos molares. Então, o prognóstico de um dente em tal condição deve ser cauteloso e as terapias necessárias devem ser realizadas. $^{7-10}$ Diante disso, na década passada, houve avanços significativos nos procedimentos de regeneração periodontal. Enxerto de materiais ósseos e derivados de matriz de esmalte, demonstraram promover a regeneração periodontal e 0 restabelecimento da fixação dentária em defeitos intraósseos. ${ }^{11-13}$

Atualmente diferentes biomateriais são utilizados para regeneração de defeitos ósseos em furcas, como os: enxertos ósseos autógenos, enxerto ósseo homógeno ou alogênico, enxertos ósseos xenógenos ou biomateriais aloplásticos [hidroxiapatita, beta-tricálcio fosfato $(\beta$ TCP), colágenos e polímeros - PLGA ${ }^{5-8}$. Todos estes biomateriais têm potencial para osteogênese ou osseocondução ${ }^{5}$. No entanto, o autoenxerto é disponível em volume limitado (calvária ou ilíaco); o aloenxerto pode ser responsável por 
infecções convencionais e não convencionais e ossos xenogênicos também podem transmitir infecção não convencional. ${ }^{8,10}$

$O$ biomaterial $\beta$-TCP pertence à família dos fosfatos tricálcicos na fase beta, sendo consideravelmente mais reabsorvível que a hidroxiapatita, esse biomaterial é altamente biocompatível quando implantado no osso; e é reabsorvível dentro de 6 a 9 meses $^{19,21}$. Uma das principais características do composto é estar disponível comercialmente com macroporosidade de 100 a $600 \mu \mathrm{m}$ que garante osteocondução e pode atingir $85 \%$ da massa total do material enxertado. Também possui microporosidade $(<100 \mu \mathrm{m})$ devido à sinterização de grãos elementares, o que facilita a troca de fluxos extracelulares dos íns $\mathrm{Ca} 2+$ e PO43. Isso garante uma ótima remodelação óssea com aumento da aposição osteoblástica e da aposição do osso lamelar. Suas propriedades de biocompatibilidade, biorreabsorção e osteocondução com o osso receptor, o tornam um material confiável, especialmente em cavidades alveolares. ${ }^{18}$ Outras pesquisas com este biomaterial concluíram que os grânulos de $\beta$-TCP induzem uma baixa resposta inflamatória ${ }^{9}$. Recentemente um estudo avaliou que a técnica combinada de $\beta$-TCP com uma membrana bioabsorvível, utilizando a técnica de regeneração tecidual guiada (RTG), obteve melhores resultados em relação ao preenchimento do defeito ósseo em comparação com o $\beta$-TCP sozinho ${ }^{10}$.

A regeneração tecidual guiada ou regeneração óssea guiada (RTG/ROG) são procedimentos cirúrgicos odontológicos que utilizam membranas de barreira para direcionar o crescimento de novos ossos e tecidos gengivais em locais com volumes ou dimensões insuficientes de osso ou gengiva para o funcionamento adequado, estética ou restauração protética. Refere-se a procedimentos de aumento da crista ou regeneração óssea e/ou a regeneração da inserção periodontal ${ }^{13-17}$. O enxerto ósseo utilizado em conjunto com a técnica de RTG é considerado um procedimento confiável e validado $^{15,16}$.

Tendo em vista o desafio do tratamento cirúrgico regenerador das lesões de furca em molares mandibulares e a necessidade de novas abordagens de tratamento, que contribuam para manutenção do dente em função, este trabalho tem como objetivo, através de uma revisão de literatura, esclarecer dúvidas a respeito do biomaterial (VITAGRAFT) composto por B-TCP e PLGA em tratamento regenerativo de lesões de furca grau II, em molares mandibulares

\section{METODOLOGIA}

O presente artigo foi desenvolvido com base em estudos científicos publicados no período de 2000 a 2020 em inglês e português nas bases de dados PubMed, Scielo e Semantic Scholar. Inicialmente, a busca foi feita utilizando-se os seguintes termos: defeitos de furca, molares mandibulares, regeneração periodontal, membrana periodontal e Beta-TCP. A busca na base de dados resultou em 84 artigos e após a leitura e análise destes, foram selecionados 23 trabalhos que atenderam ao objetivo desta revisão de literatura: $O$ Uso de biomaterial composto por $\beta$-TCP e 
PLGA em tratamento regenerativo de lesões de furca grau II em molares mandibulares.

\section{RESULTADOS}

Furca: Uma progressão da doença periodontal

A doença periodontal é uma condição inflamatória crônica que afeta os tecidos de suporte dos dentes, levando à perda óssea e do ligamento periodontal. O desenvolvimento da doença dependerá do tipo de bactéria presente, da resposta imune do hospedeiro e dos fatores locais que causam acúmulo de biofilme bacteriano ${ }^{1-3}$. Em dentes posteriores, a progressão da doença periodontal pode ocasionar reabsorção óssea na área de bi ou trifurcação de um dente de múltiplas raízes, sendo este considerado como envolvimento de furca ${ }^{3-5}$. A expressão "lesão de furca" é atribuída à perda de inserção e reabsorção óssea, ocorridos na região inter-radicular de dentes multirradiculares, ou seja, a lesão de furca se forma com uma separação atípica da raiz dos dentes do tronco radicular, dando a impressão de afastamento gengival. À medida que esta separação se intensifica, o risco de perda dentária é substancialmente aumentado. ${ }^{11}$

A furca é uma área que devido a morfologia anatômica complexa, limita o acesso à região através de instrumentos de tratamento periodontal convencional. Evidências científicas indicam que os dentes molares são mais afetados com envolvimento de furca e são extraídos com maior frequência provavelmente devido à sua anatomia ${ }^{3-6}$.

Os defeitos de furca são geralmente classificados nos graus I, II ou
III, de acordo com a perda óssea horizontal ${ }^{1}$ ou através de características como morfologia, perda óssea vertical $\mathrm{e}$ horizontal $^{2}$. É bem estabelecido que o envolvimento da furca, especificamente os graus II e III, aumenta consideravelmente 0 risco de perda dentária ${ }^{3}$.

\section{Diagnóstico e classificação das furcas}

O diagnóstico é exercido por meio de um exame clínico detalhado, como a sondagem da área comprometida com sonda Nabers, sendo complementado por exames de imagem para a avaliação da quantidade de osso presente, cristas ósseas alveolares, quantidade de perda óssea, espessura do ligamento periodontal $e$ integridade da lâmina dura. ${ }^{2}$

Vale ressaltar que a furca representa um sítio periodontal único com características anatômicas específicas e, consequentemente, com implicações clínicas e terapêuticas importantes. Sendo assim, o nível de destruição periodontal na área da lesão, pode variar de paciente para paciente e em um mesmo paciente de sítio para sítio ${ }^{11,12}$.

Dentre as classificações propostas, a mais usada é a de Hamp ${ }^{11,12}$ et al. (1975), baseada na quantidade de destruição periodontal na direção horizontal presente na área inter-radicular. São propostos três tipos de envolvimento. Na lesão de furca classe I, a perda horizontal do tecido de suporte é menor que $3 \mathrm{~mm}$; na classe II a perda horizontal do tecido de suporte é maior ou igual a $3 \mathrm{~mm}$, mas não envolve toda a extensão da área de furca; e na classe III ocorre a perda horizontal dos tecidos periodontais de um lado a outro da 
furca. $\mathrm{Na}$ prática, a classificação não considera as causas e as exigências para a manutenção da lesão. Ou seja, a furca pode: I) ser consequência de progressão da doença periodontal; II) ter origem endodôntica; III) estar associada a alterações morfológicas; ou IV) ser consequência de invasão do espaço biológico por cárie ou restaurações. Desta forma, cada situação exigirá uma abordagem diferente. Assim, é de extrema importância determinar a extensão da furca envolvida, para diagnóstico apropriado e elaboração de um plano de tratamento. ${ }^{11}$

\section{Tratamentos para lesões de furca}

Como para qualquer lesão periodontal, o tratamento dos dentes com lesões com envolvimento de furca é focado na redução de carga bacteriana supra e subgengival, através de instruções de higiene e terapia periodontal não cirúrgica, com o objetivo de eliminar o biofilme bacteriano das superfícies radiculares afetadas. O tratamento de um dente com múltiplas raízes com envolvimento de furca ainda é um desafio e um problema que, até o momento, não foi resolvido. O tipo de dente e o grau de envolvimento da furca foram definidos como os fatores mais importantes que influenciam esta decisão. ${ }^{4}$

Defeitos de furca podem ser um dos critérios considerados pelos dentistas para indicar a extração de dentes periodontalmente envolvidos e seus tratamentos são considerados desafiadores. O acesso à região de furca é difícil tanto para o dentista quanto ao paciente, e seu tratamento envolve debridamento para procedimentos de regeneração. $^{8}$

\section{Regeneração tecidual guiada/ Regeneração óssea guiada}

Evidências substanciais indicam que, independentemente da idade, a gravidade da doença periodontal e a mortalidade dentária são mais pronunciadas nos molares. Então, o prognóstico de um dente em tal condição deve ser cauteloso e as terapias necessárias devem ser realizadas. $^{7-10}$ Diante disso, na década passada, houve avanços significativos nos procedimentos de regeneração periodontal. Enxerto de materiais ósseos e derivados de matriz de esmalte, demonstraram promover a regeneração periodontal e 0 restabelecimento da fixação dentária em defeitos intraósseos. ${ }^{11-13}$

A regeneração tecidual ou óssea guiada, envolvem procedimentos cirúrgicos odontológicos que utilizam membranas de barreira para direcionar o crescimento de novos ossos e tecidos gengivais em locais com volumes ou dimensões insuficientes de osso ou gengiva para o funcionamento adequado, estética ou restauração protética. Se refere a procedimentos de aumento da crista ou regeneração óssea e/ou a regeneração da inserção periodontal ${ }^{13-17}$. 0 enxerto ósseo utilizado em conjunto com a técnica de RTG é considerado um procedimento confiável e validado ${ }^{15,16}$.

De forma mais específica, a regeneração periodontal é definida como a regeneração dos tecidos de suporte do dente, incluindo osso alveolar, ligamento periodontal e cemento. Assim, regeneração tecidual guiada consiste em uma técnica que envolve a utilização de membranas, 
para permitir a repopulação do defeito periodontal por células desejáveis, resultando no chamado novo aparato de inserção. Com isso, as células que podem repovoar a superfície radicular após uma cirurgia de retalho são as células oriundas do epitélio gengival, do osso alveolar e do ligamento periodontal ${ }^{13}$.

Conseguinte a isso, o processo de cicatrização da lesão é o mecanismo primário do corpo para restaurar a integridade tecidual em uma lesão. Se a cicatrização da lesão não ocorrer apropriadamente, um rompimento crônico da barreira protetora pode levar a anormalidades fisiológicas, imunológicas e metabólicas graves. A cicatrização basicamente representa 0 processo dinâmico que envolve vários tipos de células e mediadores biológicos. Sendo assim, no sistema ativo da lesão periodontal, as células migram, diferenciam-se e proliferam; os tecidos epiteliais e conjuntivo se interagem e uma vasta gama de citocinas e moléculas da matriz extracelular, orquestram o processo todo que ocorre em fases sobrepostas ${ }^{14}$.

A cicatrização da lesão periodontal é considerada um processo mais complexo comparada à cicatrização da lesão epidérmica. O periodonto nativo inclui 0 cemento, o PDL - poli (D-ácido láctico) funcionalmente orientado, o osso alveolar e a gengiva. As interfaces entre esses tecidos, assim como a posição transgengival do dente representam um constante desafio durante a restauração das estruturas, conforme elas buscam criar uma nova conexão ao tecido duro não vascularizado e não vital da superfície radicular dentro do contexto de um sistema aberto que está permanentemente contaminado e sob uma significativa "carga bacteriana". Portanto, não é surpreendente que a cicatrização após todos os tipos de terapia gengival e periodontal possa ser bastante variável ${ }^{15,16}$.

Os achados histológicos em estudos de regeneração periodontal e os conceitos de Melcher sobre "compartimentalização" revelaram que uma nova inserção de tecido conjuntivo poderia ser prevista se as células do PDL se estabelecessem sobre a superfície radicular durante a cicatrização ${ }^{13}$. Consequentemente, as aplicações clínicas da RTG no periodonto envolvem a colocação de uma membrana de barreira física para possibilitar que a superfície radicular dentária previamente afetada com periodontite seja repovoada com células do PDL, da lâmina própria do cório gengival, das células do cemento e do osso alveolar. As técnicas de RTG utilizam membranas de barreira para auxiliar a migração das células ósseas e células do PDL para os defeitos, por impedir que as células do tecido mole penetrem nele. Esse conhecimento foi a chave para 0 desenvolvimento dos procedimentos clínicos padrões para a colocação de membrana fabricada na RTG, a qual foi recentemente combinada com o fornecimento de diferentes fatores que são incorporados para aumentar a resposta regenerativa $^{13}$.

\section{Biomateriais}

Sabe-se que os biomateriais ao entrarem em contato com os tecidos biológicos do ser humano, torna possível o tratamento, o aumento ou substituição de 
qualquer tecido ou órgão, além de permitir a restituição de determinada função do organismo. $^{23}$

Atualmente diferentes biomateriais são utilizados para regeneração de defeitos ósseos em furcas, como os: enxertos ósseos autógenos, enxerto ósseo homógeno ou alogênico, enxertos ósseos xenógenos ou biomateriais aloplásticos [hidroxiapatita, beta-tricálcio fosfato ( $\beta$ TCP), colágenos, polímeros $]^{5-8}$. Todos estes biomateriais têm potencial para osteogênese ou osseocondução ${ }^{5}$. No entanto, o autoenxerto é disponível em volume limitado (calvária ou ilíaco), o aloenxerto pode ser responsável por infecções convencionais e não convencionais e ossos xenogênicos também podem transmitir infecção não convencional. ${ }^{8,10}$

Apesar de muitos grupos de polímeros serem estudados por suas propriedades biodegradacionais, a família dos a-hidróxi ácidos são os mais estudados e com melhores resultados físicos e mecânicos ${ }^{13}$.

Dentre os poli $\alpha$-hidróxi ácidos, o poli (ácido láctico) (PLA) e o poli (ácido glicólico) (PGA) são os mais utilizados. $O$ campo de aplicação destes polímeros é vasto, como implantes, materiais de sutura, próteses, materiais ortopédicos, pinos intramedulares, na área odontológica e em liberação controlada de fármacos ${ }^{13}$.Estes polímeros biorreabsorvíveis apresentam algumas propriedades benéficas como, ausência de pontos de estresse, não necessita ser removido após a cirurgia e não apresentam corrosão metálica, dentre outros $^{17}$.
O PLGA - poli (ácido lático-co-ácido glicólico) - é um copolímero biodegradável e bioreabsorvível. Suas propriedades físicoquímicas têm sido estudadas com o intuito de modular sua suscetibilidade à degradação e suas interações com células e fluidos biológicos para aplicações na área médica e odontológica ${ }^{14}$. Além disso, as membranas de ácido polilático têm apontado melhores resultados comparados a outros materiais ${ }^{15}$.

O material PTFE Politetrafluoretileno -, um material nãoreabsorvível, tem demonstrado possuir uma grande capacidade de barreira celular eficaz, com biocompatibilidade regular. Contudo, por serem não reabsorvíveis, apresentam uma grande desvantagem que é a necessidade de realização de uma segunda cirurgia para ser removido, o que aumenta não só a incidência da doença, como afeta o prognóstico do tratamento, expondo o tecido neoformado adjacente ${ }^{16}$.

A utilização da RTG para tratamento de lesões de furca tem demonstrado resultados satisfatórios independente do material de membrana utilizado, mas materiais reabsorvíveis como o PLGA tem se sobressaído devido 0 conforto proporcionado ao paciente, por evitar que o mesmo seja submetido a dois procedimentos cirúrgicos. ${ }^{16}$

\section{$\beta-T C P$}

Biomateriais ósseos sintéticos, como o Beta tricálcico fosfato, foram formados a partir de compostos minerais do osso. Este biomaterial não tem a capacidade de induzir a diferenciação de células osteoprogenitoras, entretanto, 
utiliza-o como preenchimento de defeitos ósseos, o qual sensibiliza as células osteoblásticas e provoca a neoformação óssea ${ }^{17}$.

$\beta$-TCP pertence à família dos fosfatos tricálcicos na fase beta, sendo consideravelmente mais reabsorvível que a hidroxiapatita, esse biomaterial é altamente biocompatível quando implantado no osso; é reabsorvível dentro de 6 a 9 meses ${ }^{19,21}$. Uma das principais características do biomaterial é estar disponível comercialmente com macroporosidade de 100 a $600 \mu \mathrm{m}$ que garante osteocondução e pode atingir $85 \%$ da massa total do material enxertado. Também possui microporosidade $(<100 \mu \mathrm{m})$ devido à sinterização de grãos elementares, o que facilita a troca de fluxos extracelulares dos íons Ca2+ (cálcio) e PO43(fosfato). Isso garante uma ótima remodelação óssea com aumento da aposição osteoblástica e da aposição do osso lamelar. Suas propriedades de biocompatibilidade, biorreabsorção e osteocondução com o osso receptor, o tornam um material confiável, especialmente em cavidades alveolares. ${ }^{18}$

Diante disso, o Beta tricálcico fosfato (B-TCP) é um material sintético (cerâmica porosa) que possui especificidades biológicas de biocompatibilidade, sendo reabsorvível pelo organismo, além de funcionar como um arcabouço para crescimento ósseo. Vale ressaltar, que o mesmo é um material extensamente testado em animais para comprovar sua capacidade como biomaterial para regeneração óssea. Temse evidenciado bons resultados clínicos em cirurgias odontológicas, médicas e na área biológica. O uso na odontologia vai desde a proteção do tecido pulpar em dentes com vitalidade até a utilização em regeneração óssea em defeitos ósseos solitários ou incorporados aos implantes ${ }^{17}$.

Por ser um material sintético, o Beta tricálcico fostato pode se apresentar em forma de cimentos, blocos, grânulos, ou ainda em misturas com Hidroxiapatita. Algumas formulações deste composto ainda podem receber um revestimento de fator de crescimento humano recombinante fator-5 (rhGDF-5). Percebe-se que a utilização do BTCP deve ter a indicação correta para uma neoformação óssea eficiente da área enxertada ${ }^{18}$.

\section{Vitagraft}

O Vitagraft (DMC group) é um produto médico/odontológico implantável e reabsorvível. Este produto foi projetado para ser utilizado como substituto ósseo, composto para enxertia, ou seja, para o preenchimento de qualquer tipo de falha óssea. É um produto absorvido $\mathrm{e}$ metabolizado pelo organismo formando novo tecido ósseo. É utilizado em cirurgias tais como (mas não exclusivamente) preenchimento de cavidades e defeitos ósseos orofaciais, intra dental e no crânio; cirurgias crânio-maxilo facial, incluindo mandíbula; Cirurgias ortopédicas e traumatologia. Pode ser utilizado isolado ou em combinação com ossos autógenos, ou ainda, em conjunto com outros biomateriais. Sua formulação é composta por $\beta$-TCP ( $\beta$ Fosfato Tricálcico) - 30\% e PLGA (Ácido polilático glicólico) $-70 \%{ }^{20-22}$.

Seu mecanismo de ação baseia-se na transformação do $\beta$-TCP, onde os 
espaços dentro da matriz começam a serem formados, os chamados arcabouços (ação osteocondutora). Esse arcabouço é utilizado para a infiltração vascular, fixação e proliferação celular (células mesenquimais sendo transformadas em osteoblastos ação osteoindutora). Esses são requisitos fundamentais para a rápida integração do biomaterial, reabsorção e subsequente substituição óssea. Durante a degradação, o $\beta$-TCP, mantém o pH maior na área do implante. $\mathrm{O}$ pH maior neutraliza o ambiente ácido associado com a degradação do PLGA. Um pH neutro oferece como vantagem uma reatividade local maior para - implante e uma redução da resposta inflamatória durante a reabsorção. Posteriormente, o PLGA vai se degradando, formando também grandes arcabouços, aumentando assim a vascularização da área e contribuindo com 0 processo de osteogênese ${ }^{20-22}$.

Como em qualquer tipo de cirurgia de implante, o paciente poderá sentir desconforto nos primeiros dias do pósoperatório. Poderá ser observada/ocorrer alguma pressão na pele ou gengiva devido ao material de enxerto com inadequada cobertura com tecido mole, incluindo a possibilidade de completa ou parcial extrusão. Além das citadas, reações normais em cirurgias periodontais poderão ser encontradas como: edema do tecido intraoral, sensibilidade térmica, recessão da gengiva e alguma perda de altura de osso cristal. $^{20,21}$

Por fim, sua forma de apresentação é composta por pó, grânulos, blocos, cunha e fios, ambos para misturar com água para injetável, soro fisiológico, plasma rico em plaquetas (PRP) ou o próprio sangue do paciente. Não possuem função de suporte mecânico, apenas de preenchimento. As opções bloco, cunha e fio foram disponibilizadas para que a atividade cirúrgica fosse realizada mais rapidamente. ${ }^{20}$

\section{DISCUSSÃO}

A furca é uma área que devido a morfologia anatômica complexa, limita o acesso à região através de instrumentos de tratamento periodontal convencional. Com isso, vários estudos foram realizados na tentativa de encontrar um método de regeneração periodontal que diminuísse o desconforto para $o$ paciente e que apresentasse praticidade e eficácia durante e após sua utilização..$^{4-6}$

Apesar do enxerto ósseo autógeno ser considerado ideal, sua obtenção pode gerar transtornos, como duas feridas ou acessos cirúrgicos, maior morbidade pósoperatória, maior tempo de cicatrização e tempo cirúrgico, dentre outros. Por esse desalento causado ao paciente, e por possíveis complicações como dor, hematomas, parestesias e aumento de infecções pós-cirúrgicas, diversos autores têm buscado outras possibilidades, como a utilização de biomateriais de origem sintética que apresentem propriedades equivalentes aos materiais de origem biológica. ${ }^{23}$

Estudos clínicos, em que diferentes materiais de membrana foram testados, compararam a técnica da RTG com o debridamento cirúrgico somente no 
tratamento de defeitos de furca classe II em molares mandibulares. Quando a membrana não absorvível de politetrafluoroetileno expandido (PTFE-e) foi usada, os resultados encontrados foram muito variados, e em algumas pesquisas as diferenças entre os tratamentos não foram clinicamente significativas. Com a utilização da segunda geração de membranas (as absorvíveis), os resultados clínicos encontrados também foram variados. Porém alguns resultados foram clinicamente favoráveis para a técnica da RTG, principalmente quando a membrana à base de ácido polilático foi empregada ${ }^{11,13,15}$.

Outras pesquisas com este biomaterial concluíram que os grânulos de $\beta$-TCP induzem uma baixa resposta inflamatória9 ${ }^{9}$ Recentemente um estudo avaliou que a técnica combinada de $\beta$-TCP com uma membrana bioabsorvível, utilizando a técnica de regeneração tecidual guiada (RTG), obteve melhores resultados em relação ao preenchimento do defeito ósseo em comparação com o $\beta$-TCP sozinho ${ }^{10}$.

Diante disso, o biomaterial eleito deve apresentar dentre suas características, biocompatibilidade,

propriedades osteocondutoras e osteoindutoras, sendo reabsorvido de forma gradativa, ao passo que um novo osso viável é formado. ${ }^{17,20}$

Dentre os biomateriais citados, $\beta$ TCP e PLGA, demonstraram resultados satisfatórios nas regenerações teciduais e ósseas guiadas em casos de furca $e$ procedimentos de enxertia, por apresentarem características ideais, como biocompatibilidade, biorreabsorção e osteocondução. ${ }^{9}$ Com isso, o VitaGraft é um material de predileção por conter em sua composição os biomateriais supracitados, cumprindo com o objetivo de reabilitar de forma íntegra regiões intrabucais com diagnóstico de furca grau II em dentes posteriores. Ainda devido a sua versatilidade, taxa de complicações reduzida e bons resultados a longo prazo, 0 $\beta$-TCP e PLGA, apresentaram-se como um material adequado para o preenchimento de defeitos ósseos. ${ }^{7,8,10}$

Autores relataram um caso clínico no qual foi utilizado osso homólogo para reconstrução de um defeito ósseo na maxila, que impossibilitava reabilitar com implantes. Demonstrou-se por meio de análises clínicas e histológicas, que o uso do osso homólogo, pode ser uma alternativa viável, uma vez que possui a vantagem de requerer apenas um acesso cirúrgico para a reabilitação com o mesmo. ${ }^{23}$

Em paralelo a isso, concluiu-se que os diferentes tipos de biomateriais têm demonstrado resultados positivos, principalmente combinados a técnica cirúrgica de regeneração óssea/tecidual guiada, sendo promissora a utilização dos mesmos, em virtude da diminuição de morbidade pós-operatória. 13,15,17.

Materiais não absorvíveis limitam a formação óssea e os mecanismos biológicos que configuram o processo de cicatrização do tecido, inclusive nas situações de enxertia. ${ }^{23}$ Assim, os materiais aloplásticos ou reabsorvíveis, são cada vez mais usados como substitutos ósseos, por serem biologicamente compatíveis com os tecidos adjacentes, além de induzirem o crescimento e remodelação óssea, mantendo a homeostasia e as 
características essenciais dos tecidos ósseos. ${ }^{17}$

\section{CONSIDERAÇÕES FINAIS}

Os biomateriais são aplicados apenas em áreas a serem reconstruídas evitando um segundo leito cirúrgico doador, reduzindo o trauma pós cirúrgico e a morbidade, além de promover um transoperatório rápido e seguro. $\mathrm{O}$ Biomaterial à base de beta-tricálcio fosfato em união ao PLGA (vitaGraft), constitui um material viável para os procedimentos de enxertia e/ou regeneração periodontal de lesões de furca em dentes posteriores mandibulares, pois suas propriedades de biocompatibilidade, biorreabsorção e osteocondução com o osso receptor, o tornam um material concorde, especialmente em cavidades alveolares.

\begin{abstract}
Objective: This study aims to evaluate a biomaterial composed of $\beta-T C P$ and PLGA in regenerative treatment of furcation grade II in mandibular molars. Method: Scientific studies published between 2000 and 2020 in English and Portuguese were used in the PubMed, Scielo and Semantic Scholar databases. The search in the database resulted in 84 articles and after reading and analyzing them, 23 papers were selected that met the objective of this literature review. Discussion: Non-absorbable materials limit bone formation and the biological mechanisms that configure the tissue healing process, even in grafting situations. Thus, alloplastic or resorbable materials are increasingly used as bone substitutes, as they are biologically compatible with adjacent tissues, in addition to inducing bone growth and remodeling, maintaining homeostasis and the essential characteristics of bone tissues. Among the biomaterials cited, $\beta$-TCP and PLGA, demonstrated satisfactory results in tissue and bone regeneration guided in cases of furcation and grafting procedures, as they present ideal characteristics, such as biocompatibility, bioreabsorption and osteoconduction. Conclusion: Beta-tricalcium phosphate in union with PLGA (vitaGraft), is a viable material for grafting procedures and / or periodontal regeneration of furcation lesions in mandibular posterior teeth.
\end{abstract}

\title{
KEYWORDS
}

Furca defects; Periodontal regeneration; Periodontal membrane; Beta-TCP.

\section{REFERÊNCIAS}

1. Jenabian N, Haghanifar S, Maboudi A, Bijani A. Clinical and radiographic evaluation of Bio-Gen with biocollagen compared with Bio-Gen with connective tissue in the treatment of class II furcation defects: a randomized clinical trial. [Internet]. Revista Scielo. 2013 [acesso em 2019 ago 22]; 21(5): 422-429. Disponível em: http://www.scielo.br/scielo.php?script=sci _arttext\&pid=S167877572013000500422.

2. Müller H.P, Eger T. Furcation diagnoses. Journal of Clinical Periodontology. 1999; 26(8): $\quad 98-435 . \quad$ DOI https://onlinelibrary.wiley.com/doi/abs/10. 1034/j.1600-051X.1999.260801.x.
3. Nibali $L$ et al. Tooth loss in molars with and without furcation involvement - a systematic review and meta-analysis. Journal of Clinical Periodontology. 2016; 43(2): 66-156. PubMed; PMID 26932323.

4. Heitz-Mayfield L. J. A, LANG N. P. Antimicrobial Treatment of Peri-implant Diseases. The International Journal of Oral \& Maxillofacial Implants. 2004; 19(1):128-139. PubMed; PMID 15635953.

5. Huynh-BA $G$ et al. The effect of periodontal therapy on the survival rate and incidence of complications of multirooted teeth with furcation involvement after an observation period 
of at least 5 years: A systematic review. Journal of Clinical Periodontology. 2009; 36(2): 76-164. PubMed; PMID 19207893.

6. Karoussis I.K et al. Long-term implant prognosis in patients with and without a history of chronic periodontitis: A 10-year prospective cohort study of the ITI Dental Implant System. Clinical Oral Implants Research. 2003; 14(3): 39-329. PubMed; PMID 12755783.

7. Avila-Ortiz G, De Buitrago JG, Reddy MS. Periodontal regeneration - furcation defects: a systematic review from the AAP Regeneration Workshop. Journal of Periodontology. 2015; 86(2): 30-108. PubMed; PMID 25644295.

8. Reddy M.S et al. Periodontal regeneration - furcation defects: a consensus report from the AAP Regeneration Workshop. Journal of Periodontology. 2015; 86(2): 3-131. PubMed; PMID 25644296.

9. Salvi G. E. et al. Risk factors associated with the longevity of multi-rooted teeth. Long-term outcomes after active and supportive periodontal therapy. Journal of Clinical Periodontology. 2014; 41(7): 7701. PubMed; PMID 24766602.

10. Kini V, Nayak D. G, Uppoor A. S. A clinical evaluation of biphasic calcium phosphate alloplast with and without a flowable bioabsorbable guided tissue regeneration barrier in the treatment of mandibular molar class II furcation defects. The Journal of Contemporary Dental Practice. 2016; 17(2): 8-143. PubMed; PMID 27207003.

11. Deliberador T.M, Nagata M.J.H, Furlaneto F.A.C, Messora M.R, Bosco A. F, Garcia V. G, Santos F.R. Abordagem conservadora no tratamento dos defeitos de furca. Revista Sul-Brasileira de Odontologia. [Internet]. 2008 [acesso em 2019 set 26]; 5(3): 50-55. Disponível em: https://pdfs.semanticscholar.org/db2f/e5b b65aa51ad4a3219e02390beca4461d92a .pdf.

12. Silva G.P et. al. Classificação e tratamento de lesão de furca. Revista Ciências da Saúde. [Internet]. 2014 [acesso 2019 set 26]; 16(2): 112-118.

Disponível em: http://www.periodicoseletronicos.ufma.br/i ndex.php/rcisaude/article/view/4082/216.

13. Moura L.A. Utilização de membranas de poli (L-ácido láctico) em regeneração tecidual guiada para periodontia. [Dissertação de Mestrado] [Internet]. São Paulo: Universidade Estadual de Campinas, Faculdade de Engenharia Mecânica, Campinas; 2007. [acesso em 2019 set 26]. Disponível em: http://www.repositorio.unicamp.br/handle/ REPOSIP/263879.

14. Rezende C. A et al. Membranas de poli (ácido lático-co-ácido glicólico) como curativos para pele: degradação in vitro e in vivo. Polímeros. Revista Scielo, 2005 [acesso em 2019 set 30]; 15(3): 232-238. Disponível em: http://www.scielo.br/scielo.php?script=sci _arttext\&pid=S0104$14282005000300015 \&$ lng $=p t \& n r m=i s o$.

15. Ferreira M.S. Tratamento das lesões de furca grau II - abordagem ressectiva vs. Regeneradora. 42f. [Dissertação de Mestrado] [Internet]. Lisboa: Universidade de Lisboa, Faculdade de Medicina Dentária; 2014. [acesso 2019 set 26]. Disponível em: https://repositorio.ul.pt/bitstream/10451/2 5481/1/ulfmd02941_tm_Marina_Ferreira. pdf.

16. Sanz M, Giovannoli J. L. Focus on furcation defects: guided tissue regeneration. Periodontology. 2000; 22(1): 169-189. DOI https://doi.org/10.1034/j.16000757.2000.2220111.x.

17. Li J. et al. Biological performance in goats of a porous titanium alloy- biphasic calcium phosphate composite. Biomateriais. 2007 [acesso 2019 set 29]; 28(1): 4209-4218. Disponível em: 10.1016/j.biomaterials.2007.05.042.

18. Keating J.F, Mcqueen M.M. Substitutes for autologous bone graft in orthopaedic trauma. The Journal of Bone and Joint Surgery. 2001; 83(1):3-8. DOI 
https://doi.org/10.1302/0301620X.83B1.0830003.

19. Peres M. F. S. Avaliação clínica do uso das proteínas derivadas da matriz do esmalte e do $\beta$-tricálcio fosfato associado à hidroxiapatita em lesões de bifurcações interproximais classe II. 99f. [Dissertação de Mestrado] [Internet]. Piracicaba: Universidade Estadual de Campinas; 2011. [acesso 2019 set 02]. Disponível em:

http://repositorio.unicamp.br/jspui/handle/ REPOSIP/287913.

20. Napolitano M.A. Boletim de informação técnica VITAGRAFT. DMC: São Carlos, 2016.

21. Sampaio A.B. Efeitos de um enxerto biofuncional e da terapia laser de baixa intensidade em defeitos ósseos induzidos em tíbias de ratos. [Tese de Doutorado] [Internet], Botucatu: Universidade Estadual Paulista, Faculdade de Medicina Veterinária e Zootecnia, 2019. [acesso 2019 nov 07]. Disponível em: https://repositorio.unesp.br/bitstream/han dle/11449/183393/sampaio_aba_dr_bot.p $\mathrm{df}$ ? sequence $=3 \&$ isAllowed $=y$.

22. Schardosim M.G. Síntese e caracterização de compósitos tipo PLGAapatita/biovidro macroporosos para aplicações biomédicas. [Tese de Doutorado] [Internet], Porto Alegre: Pontifícia Universidade Católica do Rio Grande do Sul, Faculdade de Engenharia; 2016. [acesso 2019 nov 07]. Disponível em: http://tede2.pucrs.br/tede2/bitstream/tede /6999/2/TES_MARIANE_GIACOMINI_SC HARDOSIM_COMPLETO.pdf.

23. Ribeiro C.L.C, Da cunha J.F.M, Cândido P.H, Motão J.C, Oliveira P.R.D, Borges G.J. Instalação do implante dentário após levantamento do seio maxilar com $\beta$ tricálcio fosfato: Relato de caso com resultados histológicos. INPerio. 2016; 1(3): 595-601. 